\title{
Association of RGS2 Gene Polymorphisms with Suicide and Increased RGS2 Immunoreactivity in the Postmortem Brain of Suicide Victims
}

\author{
Huxing Cui', Naoki Nishiguchi', Elena Ivleva', Masaya Yanagi', Masaaki Fukutake', Hideyuki Nushida ${ }^{2}$, \\ Yasuhiro Ueno' ${ }^{2}$ Noboru Kitamura ${ }^{3}$, Kiyoshi Maeda' and Osamu Shirakawa*,' \\ 'Department of Psychiatry and Neurology, Kobe University Graduate School of Medicine, Kobe, Japan; ²Department of Legal Medicine, Kobe \\ University Graduate School of Medicine, Kobe, Japan; ${ }^{3}$ Department of Psychiatry and Neurology, Kobe General City Hospital, Kobe, Japan
}

\begin{abstract}
Regulators of G-protein signaling are a family of proteins that negatively regulate the intracellular signaling of $G$ protein-coupled receptors, such as the serotonin receptor. Recent studies have suggested that one of these proteins, the regulator of G-protein signaling 2 (RGS2), plays an important part in anxiety and/or aggressive behavior. To explore the involvement of the RGS2 gene in the vulnerability to suicide, we screened Japanese suicide victims for sequence variations in the RGS2 gene and carried out an association study of RGS2 gene polymorphisms with suicide victims. In the eight identified polymorphisms that were identified by mutation screening, we genotyped four common single-nucleotide polymorphisms (SNPs) in the RGS2 gene, and found significant differences in the distribution of the SNP3 (C + 297IG, rs4606) genotypes and alleles of the SNP2 (C-395G, rs2746072) and the SNP3 between completed suicides and the controls. The distribution of the haplotype was also significantly different between the two groups (global $p<0.000 \mathrm{I}$ ). Furthermore, RGS2 immunoreactivity significantly increased in the amygdala and the prefrontal cortex (Brodmann area 9 (BA9)) of the postmortem brain of the suicide subjects. These findings suggest that RGS2 is genetically involved in the biological susceptibility to suicide in the Japanese population.

Neuropsychopharmacology (2008) 33, I537- 1544; doi: 10.1038/sj.npp. I30 I557; published online 29 August 2007
\end{abstract}

Keywords: regulator of G-protein signaling 2 (RGS2); suicide; gene polymorphism; anxiety; aggression; postmortem brain

\section{INTRODUCTION}

Suicide ranks among the top 10 causes of death for individuals of all ages (Diekstra, 1993). In Japan, there are more than 30000 deaths from suicide per year (a rate of $\sim 24 / 100000$ ), which is three times the number of deaths from traffic accidents. Therefore, there is an urgent need for suicide prevention in Japan. The pathogenesis of suicidal behavior is thought to involve many factors, including genetic factors as shown by twin, adoption and family studies (Brent and Mann, 2005; Roy and Segal, 2001; Turecki, 2001). Several studies have suggested that the genetic factors for suicide are independent of, or occur in combination with major psychiatric disorders (Mann et al, 1990).

The regulators of G-protein signaling family proteins play a key role in modulating intracellular signaling through the G protein pathways. More than 30 mammalian RGS family members have been identified (Ross and Wilkie, 2000). Their primary functions are to act as GTPase-activating

*Correspondence: Dr O Shirakawa, Department of Psychiatry and Neurology, Kobe University Graduate School of Medicine, 7-5-I, Kusunoki-cho, Chuo-ku, Kobe 650-00 I7, Japan, Tel: + 8178382 6065, Fax: +8I 78382 6079, E-mail: sirakawa@kobe-u.ac.jp

Received 29 January 2007; revised 27 July 2007; accepted 27 July 2007 proteins that negatively regulate signaling by $G$ proteincoupled receptors, such as serotonin, by accelerating GTP hydrolysis of the $\mathrm{G} \alpha$ subunit. Among this family, regulator of G-protein signaling 2 (RGS2) has recently been reported to be involved in anxiety and aggressive behavior. RGS2deficient mice displayed an increased anxiety response and decreased aggression (Oliveira-Dos-Santos et al, 2000). The genetic dissection of a behavioral quantitative trait locus study showed that RGS2 modulated anxiety in mice (Yalcin et al, 2004). Moreover, RGS2 gene polymorphisms have recently been associated with panic disorder (Leygraf $e t a l$, 2006), thus suggesting that RGS2 modulates anxiety not only in mice but also in humans.

Based on these findings, we hypothesized that RGS2 is involved in the pathophysiology of suicide through an alteration of intracellular signal transduction, such as a serotonin receptor signaling, and/or an alteration of anxiety and aggressive traits. To test this hypothesis, we investigated whether or not RGS2 gene polymorphisms are associated with suicide. We also examined RGS2 immunoreactivity in the amygdala and prefrontal cortex (Brodmann area 9 (BA9)) of postmortem brains of suicide victims and controls. The amygdala is thought to play an important role in emotional control (LeDoux, 2000; Davidson, 2002), and BA9 is one of the most informative areas for the biological 
susceptibility to suicide because some proteins were altered in this area in the postmortem brains of suicide victims (Dwivedi et al, 2002; Pandey et al, 2002; Arango et al, 1990; Arora and Meltzer, 1989; Mann et al, 1986).

\section{MATERIALS AND METHODS}

\section{Subjects}

The genotyping subjects consisted of 189 individuals who had committed suicide (127 men and 62 women; mean age $\pm S D, 47.8 \pm 17.5$ years), in whom autopsies were conducted in the Department of Legal Medicine of Kobe University Graduate School of Medicine. The controls consisted of 210 age- and gender-matched unrelated volunteers (139 men and 71 women; mean age $\pm S D$, $46.1 \pm 18.1$ years). All were healthy individuals of Japanese descent, and none manifested any psychiatric problems in brief interviews by psychiatrists.

Fourteen suicide and 16 control postmortem brain samples were used for the immunoquantification study. For the amygdala, we examined 10 suicides (age, $48.8 \pm$ 8.6 years; postmortem interval (PMI), $17.9 \pm 9.9 \mathrm{~h} ; \mathrm{pH}$, $6.5 \pm 0.3$ ) and eight controls (age, 58.1 \pm 10.4 years; PMI, $8.3 \pm 7.4 \mathrm{~h} ; \mathrm{pH}, 6.5 \pm 0.4)$ and for the BA9, we examined 11 suicides (age, $47.5 \pm 12.8$ years; PMI, $15.5 \pm 7.3 \mathrm{~h} ; \mathrm{pH}$, $6.6 \pm 0.3$ ) and 12 controls (age, $58.3 \pm 13.2$ years; PMI, $7.8 \pm 6.8 \mathrm{~h} ; \mathrm{pH}, 6.6 \pm 0.4$ ) (Table 1). Since some postmortem brain samples in the areas had been consumed, the samples used in this study were selected according to sample availability. Information about the neuropsychiatric diseases and psychotropic medications of the suicide victims was not available to us because of the ethical code. None of the control subjects had any history of neuropsychiatric disease. All brain samples were obtained from the Department of Legal Medicine of Kobe University Graduate School of Medicine, and all subjects were ethnic Japanese.

This study was approved by the Ethical Committee for Genetic Studies of Kobe University Graduate School of Medicine.

\section{Sequence Analysis for Mutation Screening}

Genomic DNA was extracted from whole blood with the sodium iodide method using a DNA Extractor WB kit (Wako Chemicals, Tokyo, Japan). We screened 20 suicide victims for genetic variations in the RGS2 gene including the whole exon regions and upstream flanking $1000 \mathrm{bp}$ by direct sequencing. The genomic structure of the RGS2 gene (GenBank accession: NM_002923) was determined according to the NCBI database (http://www.ncbi.nlm.nih.gov) and CHIP database (http:// www.chip.org). For all of these regions, we designed 13 primer pairs and the target sequences were amplified by polymerase chain reaction (PCR) with the Gene Amp PCR System 9700 (ABI, Foster City, CA, USA). The sequencing reactions were performed with an ABI PRISM 310 DNA sequencing kit (ABI, Foster City, CA, USA).

\section{Genotyping}

Of the eight SNPs that we identified by mutation screening, we genotyped four common SNPs of the RGS2 gene; A-638G (located in the upstream region, acc. no. rs2746071), C-395G (upstream, rs2746072), C+2971G ( $3^{\prime}$ untranslated region ( $3^{\prime} \mathrm{UTR}$ ), rs4606), C + 3438T (downstream, rs3767488), and denominated them SNP1-4, respectively. We used the following PCR restriction fragment-length polymorphism methods for genotyping each polymorphism. For SNP1, the target sequence was amplified by PCR with the forward primer, $5^{\prime}$-TTCTCAAAGTGTTCCAAGACG-3' ${ }^{\prime}$ and the reverse primer, $5^{\prime}$-CCTGCTGTAGGACTCATTCG- $3^{\prime}$ and the PCR products were digested with the restriction enzyme $B s r D I$. For SNP2, the target sequence was amplified with the forward primer, $5^{\prime}$-TCATTCGAAATCAGGCCACT- $3^{\prime}$ and the reverse primer, $5^{\prime}$-AGGGAGGGAGCCGAAGTT- $3^{\prime}$ and the PCR products were digested with the restriction enzyme $B s i E I$. For SNP3, the PCRs were performed with the forward primer, $5^{\prime}$-CAGTGAAGTGTTTACTATGTGCCA- $3^{\prime}$ and the reverse primer $5^{\prime}$-CCTTTATCTGCCACATTTCCA-3' and the PCR products were digested with the restriction enzyme $B s t N I$. For SNP4, the forward primer, 5'-GCAGTGTCCGT TATGAGTGC- $3^{\prime}$ and the reverse primer, $5^{\prime}$-GGAAGCC CATGCTGGTACTT- $3^{\prime}$ were used and the PCR products were digested with the restriction enzyme $B f a$ I. All PCR fragments were visualized by ethidium bromide staining and UV transillumination.

\section{Western Blot Analysis and ${ }^{3} \mathrm{H}$-Ketanserin Binding Assay}

Brain tissue samples were prepared as described previously (Lin et al, 1999). Proteins were electrophoresed in a $15 \%$ SDS-polyacrylamide gel $(5 \mu \mathrm{g} / \mathrm{lane})$. Multimark molecular mass markers (14.3 220 kDa, Amersham Bioscience, Little Chalfont, UK) were co-electrophoresed for size estimation. Proteins on the gel were transferred electrophoretically onto a polyvinylidene difluoride membrane. The membranes were incubated in phosphate-buffered saline (PBS) containing $0.1 \%$ Tween $20,5 \%$ skim dry milk overnight at $-4^{\circ} \mathrm{C}$, incubated for $2 \mathrm{~h}$ at room temperature (RT) with rabbit anti-RGS2 polyclonal antibody (sc-9103, Santa Cruz Biotechnology, Santa Cruz, CA, USA) and rabbit anti- $\beta$ actin (Abcam Ltd. Cambridge, UK) diluted to $1: 500$ and $1: 10000$, respectively, in PBS plus $2.5 \%$ skim dry milk incubation buffer, washed in incubation buffer containing $0.1 \%$ Tween $20(3 \times 10 \mathrm{~min})$ at RT, incubated for $1 \mathrm{~h}$ at RT with horseradish peroxidase-conjugated anti-rabbit IgG (Amersham Bioscience) diluted to 1:5000, washed in incubation buffer containing $0.1 \%$ Tween $20(2 \times 10 \mathrm{~min})$ at RT, rinsed in PBS, and visualized using the enhanced chemiluminescence plus technique (Amersham Bioscience). The primary antibody's specificity was confirmed in this study by a competition experiment using purified human RGS2 recombinant proteins (\#G22245F, GenWay Biotech Inc., San Diego, CA, USA) (data not shown). Densitometric readings were obtained with a luminous image analyzer LAS3000 mini and MultiGauge image analysis software program (FUJIFILM Life Science, Tokyo, Japan). The $\mathrm{pH}$ of the brain tissue was determined using the method of Johnston et al (1997).

To examine possible co-regulation of RGS2 and the serotonin $2 \mathrm{~A}$ receptor (5-HT2AR), the density of the 5HT2AR of the BA9 of control subjects was also examined by measuring ${ }^{3} \mathrm{H}-$ Ketanserin binding (Mita et al, 1986). The experiment was performed according to the one described previously (Ono et al, 2002). 
Table I Autopsy and Clinical Data of Postmortem Brain Samples

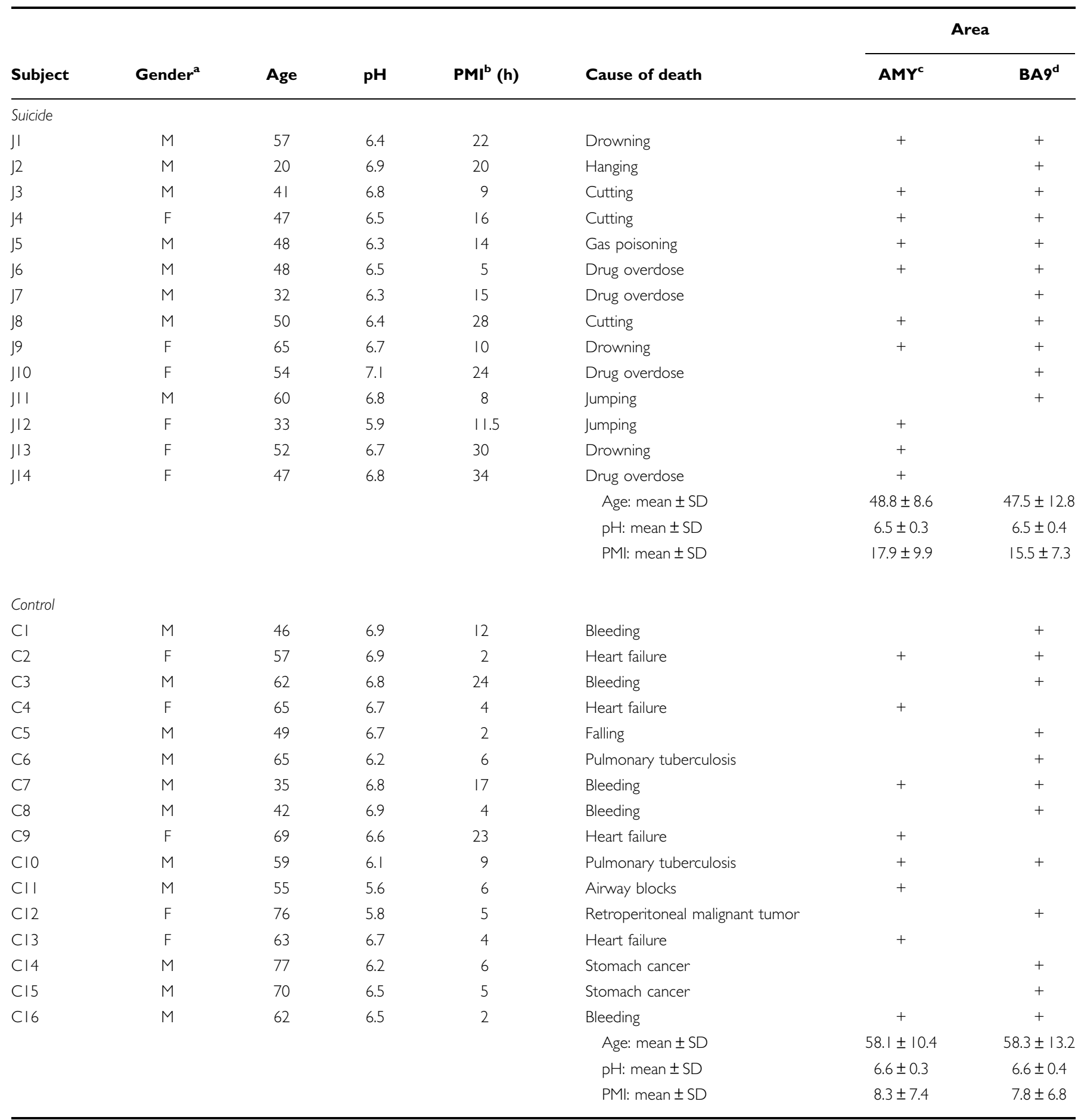

${ }^{\mathrm{a} G e n d e r, ~ M: ~ m a l e ~ F: ~ f e m a l e . ~}$

bPMl, postmortem interval.

${ }^{\mathrm{C}} \mathrm{AMY}$, amygdala.

'BA9, Brodmann Area 9.

\section{Statistical Analysis}

The genotype distribution and the allele frequencies of each polymorphism (SNP1-4) were compared between the suicide victims and the controls using a $\chi^{2}$ test. Correction for multiple testing of SNPs in linkage disequilibrium (LD) with each other was performed as described by Nyholt (2004). The effective number of independent marker loci was 1.8377, and $p<0.027$ was considered to indicate significant association with suicide. The haplotypes and the LD were analyzed with the SNPAlyze software program (DYNACOM, Yokohama, Japan) and the significance of the 
difference in immunoreactivity between the two groups was tested by Student's $t$-test. The level of significance was set at $p<0.05$.

\section{RESULTS}

We identified eight polymorphisms in the RGS2 gene by genomic screening. Three of them were located in the upstream region, four were in the exon region and one was in the downstream region (Figure 1). No polymorphisms causing amino-acid substitutions were identified. In pilot genotyping, four of the eight polymorphisms were found to have frequencies of less than $5 \%$ and thus were eliminated. The four common remaining polymorphisms, called SNP1-4, were genotyped in both the suicide and the control samples. All four of the examined SNPs were in the Hardy-Weinberg equilibrium for patients as well as for controls. Pairwise LD between the markers was between 0.87 and 0.96 . Statistically significant differences between the suicides and the controls were found in the genotype distributions of SNP3 $(p=0.011)$ and in the allele frequencies of SNP2 and SNP3 $(p=0.017$ and 0.005 , respectively) (Table 2). A haplotype analysis of
SNP1-4 detected a highly significant difference between the two groups (global $p=0.00005$ ), which was confirmed by a permutation test $(p=0.0001$ for 10000 permutations $)$ (Table 3). A combination haplotype analysis showed that the combinations including SNP3 had a relatively high significance (Table 4).

Figure 2 shows the results of a Western blot analysis of the postmortem brains of both the suicide and the control subject. Through a blot of both the anti- $\beta$-actin and antiRGS2 antibodies together, we obtained two clear bands in positions that were consistent with the previously known molecular weight for each protein (Figure 2a). The RGS2 levels were quantified by normalizing to the level of $\beta$-actin and were found to be significantly higher in the suicide group than in the controls for both the amygdala and BA9 ( $p=0.009$ and 0.03 , respectively) (Figure $2 \mathrm{~b}$ ). An analysis of all background factors in the postmortem brain samples showed the PMI to be significantly longer in the suicide group than in the control group for both the amygdala and BA9 ( $p=0.04$ and 0.02 , respectively) and the mean age of the suicidal samples was approximately 10 years younger than the control samples but the difference was not

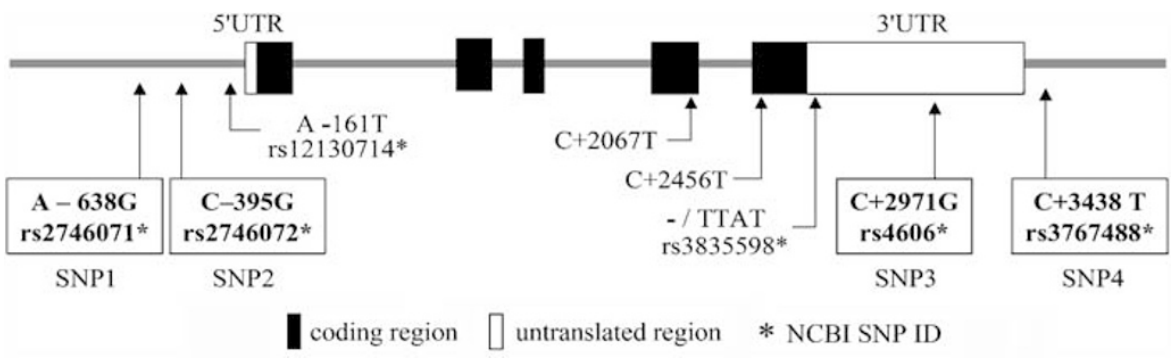

Figure I A schematic drawing of the RGS2 gene. Polymorphisms in bold letters were genotyped for association and named SNPI -4 , respectively. SNPI and SNP4 have an interval of 4076 base pairs(bp).

Table 2 Genotypes and Allele Frequencies of the Four Common Polymorphisms in RGS2 Gene

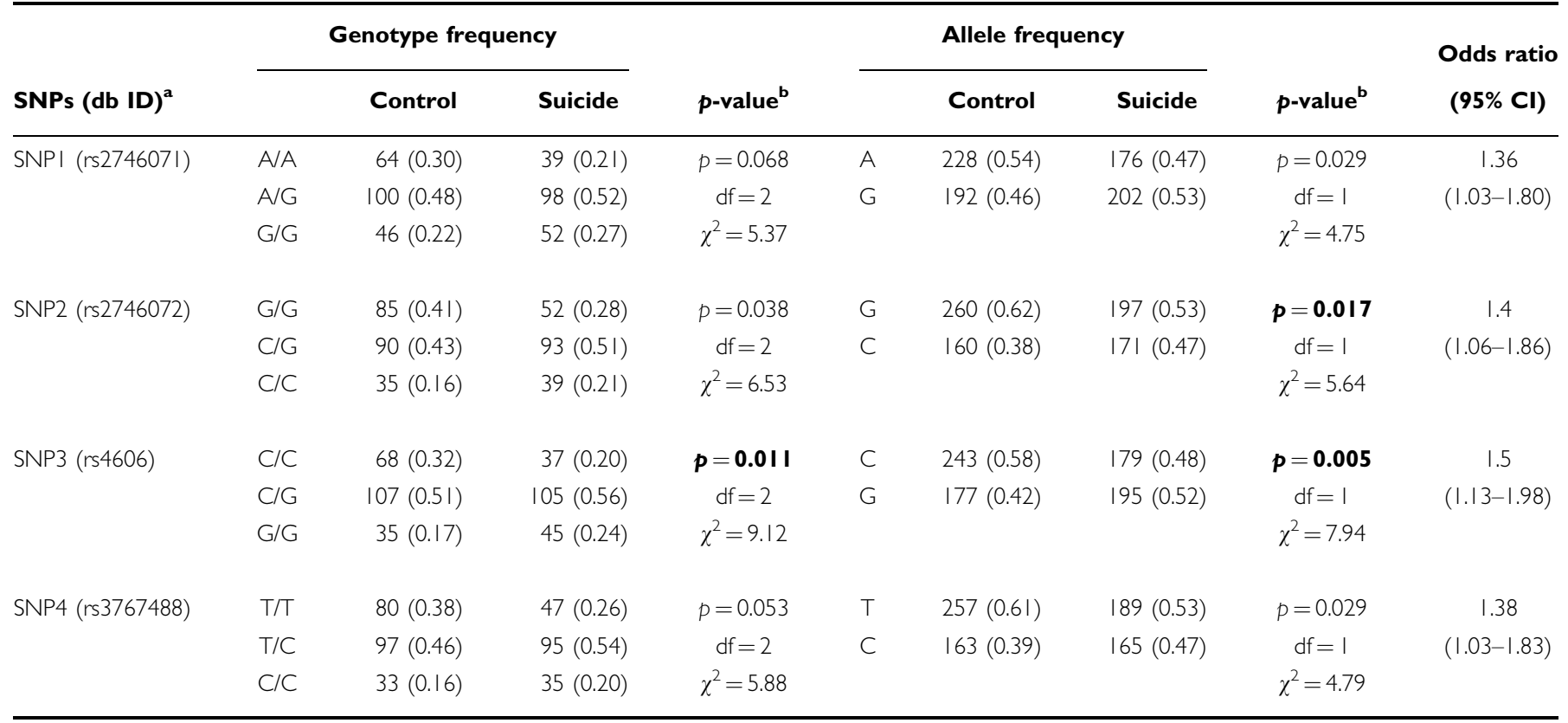

${ }^{\mathrm{a}} \mathrm{db}$ ID, database SNP number.

${ }^{b} p$-values are given in bold, when $p<0.027$. 
Table 3 Estimated Haplotype Frequencies Among Suicide Victims and Control Subjects

\begin{tabular}{|c|c|c|c|c|c|}
\hline & & \multicolumn{2}{|c|}{ Frequency } & \multicolumn{2}{|c|}{ Global $p$-value $=0.00005^{a}$} \\
\hline \multicolumn{2}{|c|}{ Haplotypes of SNP I-2-3-4 } & Control & Suicide & $\chi^{2}$ & $p$-value ${ }^{b}$ \\
\hline 2 & G-C-G-C & 0.348 & 0.427 & 5.02 & $0.025(0.033)$ \\
\hline 3 & G-G-G-T & 0.056 & 0.028 & 3.55 & 0.059 \\
\hline 6 & G-C-G-T & $<0.01$ & 0.014 & 2 & 0.157 \\
\hline 7 & $\mathrm{G}-\mathrm{C}-\mathrm{C}-\mathrm{C}$ & 0.016 & $<0.00$ I & 5.62 & $0.018(0.027)$ \\
\hline 8 & $\mathrm{~A}-\mathrm{C}-\mathrm{C}-\mathrm{T}$ & $<0.0$ । & 0.012 & 1.21 & 0.27 \\
\hline 9 & A-G-G-T & $<0.01$ & 0.012 & 1.16 & 0.281 \\
\hline 10 & G-G-C-C & 0.012 & $<0.00$ I & 4.14 & $0.042(0.04)$ \\
\hline
\end{tabular}

${ }^{a}$ Global $p$-value not conducted by permutation correction. After permutation correction, $p$-value is 0.0001 (for 10000 permutations).

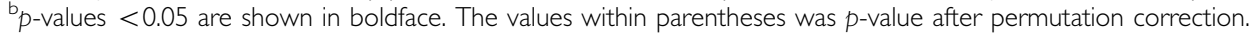

${ }^{\mathrm{c}}$ All haplotypes with estimated frequencies $<1 \%$ in both groups.

Table 4 Global p-Value of Combination Haplotype

\begin{tabular}{lcccc}
\hline & \multicolumn{4}{c}{ Number of combination } \\
\cline { 2 - 5 } SNPs & $\mathbf{1}$ & $\mathbf{2}$ & $\mathbf{3}$ & $\mathbf{4}$ \\
\hline SNPI & $\mathbf{0 . 0 2 9}$ & & & \\
SNP2 & $\mathbf{0 . 0 1 8}$ & & $\mathbf{0 . 0 1 6}$ & $\mathbf{0 . 0 0 0 0 5}$ \\
SNP3 & $\mathbf{0 . 0 0 5}$ & $\mathbf{0 . 0 3 7}$ & $\mathbf{0 . 0 0 0 0 0 7}$ & \\
SNP4 & $\mathbf{0 . 0 2 9}$ & $\mathbf{0 . 0 0 0 8}$ & & \\
\hline
\end{tabular}

${ }^{\mathrm{a}}$ Global $p$-values $<0.05$ are shown in boldface.

statistically significant. No significant differences were found regarding sex and $\mathrm{pH}$. To take into account the potential confounding effects of age and PMI on these significant results, an analysis of covariance was performed and any significant differences in both the amygdala and BA9 were observed ( $p=0.036$ and 0.046 , respectively).

Considering the involvement of the 5-HT2AR in suicide, the BA9 is an extremely intriguing area because increased level of the 5-HT2AR density in the BA9 of suicide subjects has been repeatedly reported (Pandey et al, 2002; Arango et al, 1990; Arora and Meltzer, 1989; Mann et al, 1986). To examine possible co-regulation of RGS2 and the 5-HT2AR, we examined the correlation between RGS2 immunoreactivity and ${ }^{3} \mathrm{H}$-ketanserin binding reflecting 5-HT2AR density in BA9 of normal control subjects $(n=12)$. The RGS2 immunoreactivity was significantly correlated with the 5-HT2AR level in the BA9 $(p=0.675, p=0.006)$ (Figure 3$)$.

\section{DISCUSSION}

To our knowledge, this is the first association study between RGS2 gene polymorphisms and suicide. Eight polymorph- isms were found through genomic sequencing of the RGS2 gene. Among them, we genotyped four common SNPs in both the suicide victims and the controls. The allele frequencies of SNP2 and SNP3 were significantly different between the suicide victims and the controls after multiple testing corrections. Although the significance of SNP1 and SNP4 disappeared after the correction for multiple comparisons, they were also suggestive of an association with suicide ( $p=0.029$ both together). Moreover, a highly significant difference (global $p<0.0001$ ) was obtained by a haplotype analysis of the four SNPs. These findings suggest that the RGS2 gene is involved in the biological susceptibility to suicide in Japanese.

Furthermore, the immunoreactivity level of RGS2 in the amygdala and prefrontal cortex (BA9) were significantly higher in the suicide subjects than in the controls, thus suggesting that in suicide subjects the increased RGS2 level alters GPCR intracellular signaling. Among the investigated four SNPs, the association between SNP3 and suicide was the most significant and the significant levels of the haplotypes including SNP3 were relatively high in the analysis of combination haplotype (Table 4). Though no differences in the RGS2 immunoreactivity levels in the amygdala or prefrontal cortex (BA9) were found among the SNP3 genotypes in the present study (data not shown), we cannot draw an ultimate conclusion about the biological implication of the SNP3 genotypes because of the small postmortem sample size. Further studies using larger postmortem samples and/or in vitro experiments to clarify the biological function of the SNP3 genotypes are therefore needed.

RGS2 consists of 211 amino acids, and includes a 120amino-acid RGS domain. RGS2 mainly attenuates G $\propto$ qmediated GPCR signaling (Heximer et al, 1997; Heximer, 2004). It is noteworthy that 5-HT2AR is also coupled with $\mathrm{G} \propto \mathrm{q}$ (Adlersberg et al, 2000), and its levels have been shown to be significantly higher in the prefrontal cortex (BA 8 and/ or 9) of the postmortem brains of suicide victims (Pandey et al, 2002; Mann et al, 1986; Arora and Meltzer, 1989; Arango et al, 1990). The activity of phosphoinositide- 

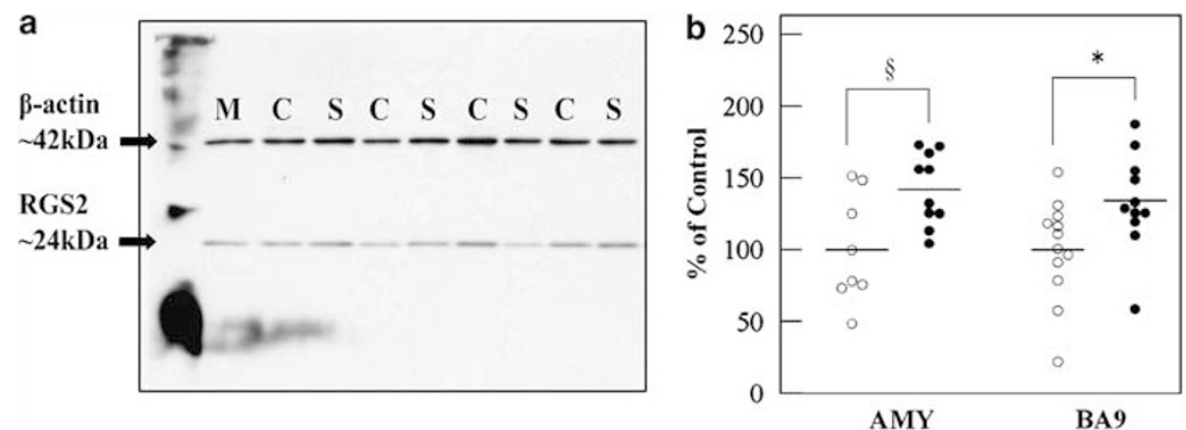

Figure 2 (a) Representative immunoblots of RGS2 protein. C: control, S: suicide, M: mixed standard. (b) The results are expressed as a percentage of the control. ${ }^{*} p<0.05 ;{ }^{\S} p<0.0$ I by Student's t-test. AMY indicates amygdala; BA9 indicates Brodmann Area 9. Open circles (O) are control subjects; Closed circles $(\mathbf{O})$ are suicide subjects.

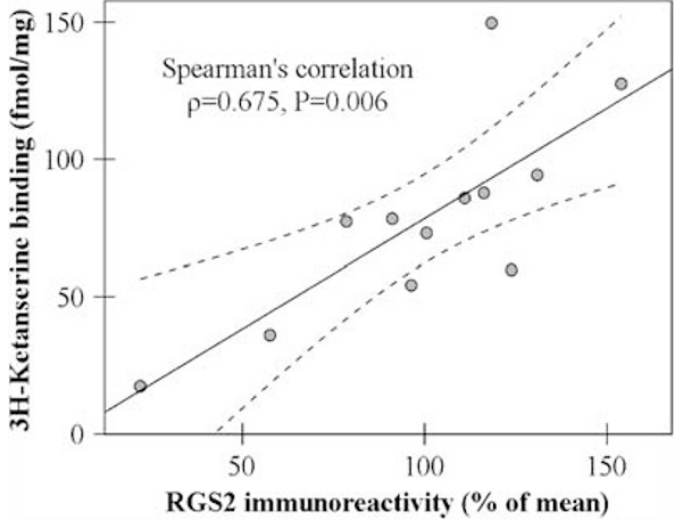

Figure 3 Correlation between RGS2 immunoreactivity and ${ }^{3} \mathrm{H}$ Ketanserin binding in the prefrontal cortex (BA9) of the control subjects $(n=12)$

specific phospholipase $\mathrm{C}$ and the level of phospholipase $\mathrm{C} \beta$, both of which are enzymes that are important 5-HT2AR intracellular signal molecules, have been shown to be significantly reduced in the prefrontal cortex (BA8/9) of the postmortem brains of suicide subjects (Pandey et al, 1999). Attempts to find an association between the genetic variations in the serotonergic system, including the 5HT2AR gene, and suicide thus far been inconclusive (Anguelova et al, 2003; Arango et al, 2003). RGS2 was found to significantly decrease G $\alpha \mathrm{q}$-mediated signaling of the 5-HT2AR in vitro (Ghavami et al, 2004). In the present study, we also examined ${ }^{3} \mathrm{H}$-ketanserin binding as a reflection of the 5-HT2AR density in the BA9, and found a significant correlation between RGS2 immunoreactivity and ${ }^{3} \mathrm{H}$-Ketanserin binding in the control group (Figure 3). Although it remains to be seen whether the polymorphisms examined in this study are involved in the RGS2 expression level and/or functional activity, the upregulation of RGS2 and consequent attenuated G $\propto$ q-mediated GPCR signaling including the 5-HT2AR in the brain may be one of the factors underlying suicidal behavior.

RGS2 knockout has been found to decrease aggression in mice (Oliveira-Dos-Santos et al, 2000). In addition, an analysis of a behavioral quantitative trait locus in mouse showed that RGS2 modulated anxiety (Yalcin et al, 2004). In animals and humans, the amygdala is believed to control emotions such as fear and anxiety and behaviors such as impulsive violence (Phelps and LeDoux, 2005; Shaikh et al, 1993). Fear, anxiety and impulsive violence have all been proposed as risk factors for suicide (Sareen et al, 2005; Dumais et al, 2005). However, evidence showing the involvement of RGS2 in either aggression or anxiety in humans is still limited. The association between RGS2 and anxiety and aggression in mice, and our finding of an increased level of RGS2 immunoreactivity in the amygdala of suicide victims, thus raises the possibility that the alteration of RGS2 contributes to suicide by dysregulating emotional control, however, the biological mechanism underlying this remains to be elucidated.

Many suicides are partly the result of psychiatric disorders. On the other hand, even in psychiatric groups at the highest risk, most patients never attempt suicide, thus suggesting that the predisposition to demonstrate suicidal behavior is independent of the main psychiatric disorders. Alterations of the serotonergic system have been repeatedly reported in suicide victims, such as the reduced concentration of 5-hydroxyindolacetic acid in the cerebrospinal fluid or the blunted prolactin response to fenfluramine, and seem to be independent of the psychiatric diagnoses and correlate with the lethality of suicide attempts (Asberg et al, 1976; Quattrone et al, 1983). Kety (1986) suggested that one of the major genetic factors in suicide may be related to an inability to control impulsive behavior in psychiatric and psychogenic conditions. In addition, a heritability of 55\% has been shown with serious suicide attempts (Statham et al, 1998). Therefore, the completed suicide samples used in this study are considered suitable for investigating the genetic factors of suicide because of their high lethality.

There are some limitations to this study. Despite the significant findings of RGS2 immunoreactivity in suicide victims we cannot draw any ultimate conclusions because of the relatively small sample size and the significant age difference and PMI between the two groups. Accordingly, further studies using well-matched large samples are thought to be in need. We could not perform any further analyses for genetic association or RGS2 immunoreactivity in the subdivided samples because of the lack of any clinical background and toxicity or psychoactive medication regarding the suicide subjects. Therefore, whether an association between RGS2 gene polymorphisms and suicide can be found in psychiatric disorders, such as depression, remains to be elucidated. Moreover, the sample size used for the genetic association study was also relatively small. 
Further studies are needed to confirm our results in independent populations using larger samples.

The RGS family proteins have attracted attention as targets of many therapeutic drugs (Zhong and Neubig, 2001), including drugs for neuropsychiatric diseases (Neubig and Siderovski, 2002). If the association between RGS2 and suicide observed in this study is confirmed and the mechanism regarding the involvement of RGS2 in suicide can be elucidated, then drugs targeting RGS2 may be developed to effectively prevent suicide.

\section{ACKNOWLEDGEMENTS}

This research was supported by a Research Grant for Nervous and Mental Disorders from the Ministry of Health, Labor and Welfare, Japan, by Grants from the Ministry of Education, Science, Culture and Sports, and by Health Sciences Research Grants from the Ministry of Health, Labor and Welfare, Japan.

\section{DISCLOSURE/CONFLICT OF INTEREST}

I declare that, except for income received from my primary employer, no financial support or compensation has been received from any individual or corporate entity over the past 3 years for research or professional service and there are no personal financial holdings that could be perceived as constituting a potential conflict of interest.

\section{REFERENCES}

Adlersberg M, Arango V, Hsiung S, Mann JJ, Underwood MD, Liu $\mathrm{K}$ et al (2000). In vitro autoradiography of serotonin 5-HT(2A/2C) receptor-activated G protein: guanosine- $5^{\prime}$ (gamma-[(35)S]thio)triphosphate binding in rat brain. J Neurosci Res 61: 674-685.

Anguelova M, Benkelfat C, Turecki G (2003). A systematic review of association studies investigating genes coding for serotonin receptors and the serotonin transporter, II. Suicidal behavior. Mol Psychiatry 8: 646-653.

Arango V, Ernsberger P, Marzuk PM, Chen JS, Tierney H, Stanley $M$ et al (1990). Autoradiographic demonstration of increased serotonin 5-HT2 and beta-adrenergic receptor binding sites in the brain of suicide victims. Arch Gen Psychiatry 47: 1038-1047.

Arango V, Huang YY, Underwood MD, Mann JJ (2003). Genetics of the serotonergic system in suicidal behavior. J Psychiatr Res 37: 375-386.

Arora RC, Meltzer HY (1989). Serotonergic measures in the brains of suicide victims: 5-HT2 binding sites in the frontal cortex of suicide victims and control subjects. Am J Psychiatry 146: $730-736$.

Asberg M, Traskman L, Thoren P (1976). 5-HIAA in the cerebrospinal fluid. A biochemical suicide predictor? Arch Gen Psychiatry 33: 1193-1197.

Brent DA, Mann JJ (2005). Family genetic studies, suicide, and suicidal behavior. Am J Med Genet C Semin Med Genet 133: 13-24.

Davidson RJ (2002). Anxiety and affective style: role of prefrontal cortex and amygdala. Biol Psychiatry 51: 68-80.

Diekstra RF (1993). The epidemiology of suicide and parasuicide. Acta Psychiatr Scand Suppl 371: 9-20.

Dumais A, Lesage AD, Alda M, Rouleau G, Dumont M, Chawky N et al (2005). Risk factors for suicide completion in major depression: a case-control study of impulsive and aggressive behaviors in men. Am J Psychiatry 162: 2116-2124.

Dwivedi Y, Rizavi HS, Conley RR, Roberts RC, Tamminga CA, Pandey GN (2002). mRNA and protein expression of selective alpha subunits of $\mathrm{G}$ proteins are abnormal in prefrontal cortex of suicide victims. Neuropsychopharmacology 4: 499-517.

Ghavami A, Hunt RA, Olsen MA, Zhang J, Smith DL, Kalgaonkar S et al (2004). Differential effects of regulator of $G$ protein signaling (RGS) proteins on serotonin 5-HT1A, 5-HT2A, and dopamine D2 receptor-mediated signaling and adenylyl cyclase activity. Cell Signal 16: 711-721.

Heximer SP (2004). RGS2-mediated regulation of Gqalpha. Methods Enzymol 390: 65-82.

Heximer SP, Watson N, Linder ME, Blumer KJ, Hepler JR (1997). RGS2/G0S8 is a selective inhibitor of Gqalpha function. Proc Natl Acad Sci USA 94: 14389-14393.

Johnston NL, Cervenak J, Shore AD, Torrey EF, Yolken RH (1997). Multivariate analysis of RNA levels from postmortem human brains as measured by three different methods of RT-PCR. J Neurosci Methods 77: 83-92.

Kety SS (1986). Genetic factors in suicide. In: Roy A (ed). Suicide. Williams and Wilkins: Baltimore. pp 41-45.

LeDoux JE (2000). Emotion circuits in the brain. Annu Rev Neurosci 23: 155-184.

Leygraf A, Hohoff C, Freitag C, Willis-Owen SA, Krakowitzky P, Fritze J et al (2006). Rgs2 gene polymorphisms as modulators of anxiety in humans? J Neural Transm 113: 1921-1925.

Lin XH, Kitamura N, Hashimoto T, Shirakawa O, Maeda K (1999). Opposite changes in phosphoinositide-specific phospholipase $\mathrm{C}$ immunoreactivity in the left prefrontal and superior temporal cortex of patients with chronic schizophrenia. Biol Psychiatry 15: 1665-1671.

Mann JJ, Arango V, Underwood MD (1990). Serotonin and suicidal behavior. Ann N Y Acad Sci 600: 476-485.

Mann JJ, Stanley M, McBride PA, McEwen BS (1986). Increased serotonin2 and beta-adrenergic receptor binding in the frontal cortices of suicide victims. Arch Gen Psychiatry 43: 954-959.

Mita T, Hanada S, Nishino N, Kuno T, Nakai H, Yamadori T et al (1986). Decreased serotonin S2 and increased dopamine D2 receptors in chronic schizophrenics. Biol Psychiatry 21: 1407-1414.

Neubig RR, Siderovski DP (2002). Regulators of G-protein signalling as new central nervous system drug targets. Nat Rev Drug Discov 1: 187-197.

Nyholt DR (2004). A simple correction for multiple testing for single-nucleotide polymorphisms in linkage disequilibrium with each other. Am J Hum Genet 74: 765-769.

Oliveira-Dos-Santos AJ, Matsumoto G, Snow BE, Bai D, Houston FP, Whishaw IQ et al (2000). Regulation of $\mathrm{T}$ cell activation, anxiety, and male aggression by RGS2. Proc Natl Acad Sci USA 97: 12272-12277.

Ono H, Shirakawa O, Kitamura N, Hashimoto T, Nishiguchi N, Nishimura A et al (2002). Tryptophan hydroxylase immunoreactivity is altered by the genetic variation in postmortem brain samples of both suicide victims and controls. Mol Psychiatry 7: $1127-1132$.

Pandey GN, Dwivedi Y, Pandey SC, Teas SS, Conley RR, Roberts RC et al (1999). Low phosphoinositide-specific phospholipase C activity and expression of phospholipase $\mathrm{C}$ betal protein in the prefrontal cortex of teenage suicide subjects. Am J Psychiatry 156: $1895-1901$.

Pandey GN, Dwivedi Y, Rizavi HS, Ren X, Pandey SC, Pesold C et al (2002). Higher expression of serotonin 5-HT (2A) receptors in the postmortem brains of teenage suicide victims. Am J Psychiatry 159: 419-429.

Phelps EA, LeDoux JE (2005). Contributions of the amygdala to emotion processing: from animal models to human behavior. Neuron 48: 175-187. 
Quattrone A, Tedeschi G, Aguglia U, Scopacasa F, Direnzo GF, Annunziato L (1983). Prolactin secretion in man: a useful tool to evaluate the activity of drugs on central 5-hydroxytryptaminergic neurons. Studies with fenfluramine. Br J Clin Pharmacol 16: 471-475.

Ross EM, Wilkie TM (2000). GTPase-activating proteins for heterotrimeric $G$ proteins: regulators of $G$ protein signaling (RGS) and RGS-like proteins. Annu Rev Biochem 69: 795-827.

Roy A, Segal NL (2001). Suicidal behavior in twins: a replication. J Affect Disord 66: 71-74.

Sareen J, Cox BJ, Afifi TO, de Graaf R, Asmundson GJ, ten Have M et al (2005). Anxiety disorders and risk for suicidal ideation and suicide attempts: a population-based longitudinal study of adults. Arch Gen Psychiatry 62: 1249-1257.
Shaikh MB, Steinberg A, Siegel A (1993). Evidence that substance P is utilized in medial amygdaloid facilitation of defensive rage behavior in the cat. Brain Res 625: 283-294.

Statham DJ, Heath AC, Madden PA, Bucholz KK, Bierut L, Dinwiddie SH et al (1998). Suicidal behaviour: an epidemiological and genetic study. Psychol Med 28: 839-855.

Turecki G (2001). Suicidal behavior: is there a genetic predisposition? Bipolar Disord 3: 335-349.

Yalcin B, Willis-Owen SA, Fullerton J, Meesaq A, Deacon RM, Rawlins JN et al (2004). Genetic dissection of a behavioral quantitative trait locus shows that Rgs 2 modulates anxiety in mice. Nat Genet 36: 1197-1202.

Zhong H, Neubig RR (2001). Regulator of G protein signaling proteins: novel multifunctional drug targets. J Pharmacol Exp Ther 297: 837-845. 